\title{
THE DEMANDINGNESS OF VIRTUE
}

\author{
Robert Weston Siscoe
}

W IOGENES famously held that there are few, if any, virtuous people. He believed that the priorities of the Athenians, pursuits like the acquisition of wealth and popularity, were inimical to living a virtuous life. In a stark demonstration of his protest of Athenian life, he wandered Athens with a lamp in broad daylight, claiming he was looking for an honest man. ${ }^{1}$ But were Diogenes's expectations too high? Our society has the same sorts of social pressures, the ever-present pull of greed and social status, yet we know many virtuous people. Even though Diogenes was right that Athenian culture was not a perfect incubator for virtue, surely he was wrong to think that this prevented its citizens from being virtuous altogether.

One way to cash out this opposing view to Diogenes is to say that virtue is a contextual matter. Whether or not someone possesses the virtue of honesty, for instance, is determined not only by the characteristics of the honest person but also by a contextual threshold for what is considered virtuous. On this account, it is possible that Athenians were virtuous so long as they were virtuous enough given their society. "Virtuous" and "honest," after all, are gradable adjectives, and number of gradable adjectives do function with a contextual threshold. What is considered an expensive handbag may vary by social class, and what is called a long road may vary by county, making it plausible that the truth of gradable virtue adjectives also factors in context. In section 1, I further detail such contextual views of gradable adjectives, showing that they can be used as a response to Diogenes's criticism of the Athenians.

Before taking such contextual proposals on board, however, closer attention is needed to which sorts of gradable adjectives function with a contextual threshold. Contemporary work on gradable adjectives has differentiated be-

1 Diogenes Laertius, Lives of Eminent Philosophers, bk. IV, ch. 41. The more accurate translation of what Diogenes inquires as he is traveling through the streets is that "he is looking for a man." The reason that he cannot find one is that he takes man to be essentially rational, but by living apart from virtue, the citizens of Athens are also not living completely rational lives. This then leads to Diogenes's criticism that he cannot find a man as he cannot find anyone completely virtuous and thus rational. 
tween absolute and relative gradable adjectives, a distinction whose explanatory power has quickly made it widely accepted within linguistics. ${ }^{2}$ Despite the recent uptake of the divergence between absolute and relative gradable adjectives in linguistics, however, the contrast between them has been largely ignored within philosophy. ${ }^{3}$ In sections 2 and 3 , I introduce the relative/absolute distinction, showing that relative gradable adjectives typically function with a contextual threshold. When terms like "virtuous" and "honest" are also taken to be relative gradable adjectives, the natural result is an account on which their truth conditions differ along with the context.

The contextual threshold view is problematic, however, because "virtuous" and "honest" are absolute gradable adjectives, or so I argue in section 4. Unlike relative gradable adjectives, the denotation of absolute gradable adjectives remains fixed on the maximal element in the underlying scale regardless of context. Absolute gradable adjectives are thus not context sensitive, and so a context-dependent view will be of no use in replying to Diogenes. Terms like "honest" and "just" can only be used to specify something besides the highest point in their scales when they are used imprecisely, but imprecise attributions of "virtuous," "honest," and "just" are all literally false. For this reason, I will argue that Diogenes was correct in thinking that a number of the virtues require perfection and that there were perhaps none who were truly virtuous in Athenian society. Diogenes and his followers are not mistaken about the truth-conditions of "honest"; they simply refuse to use "honest" imprecisely.

\section{VICIOUS CULTURES, VIRTUOUS CITIZENS}

Diogenes's critique, that a corrupt culture risks the virtue of its citizens, has maintained its appeal for contemporary virtue ethicists. Julia Annas argues that, because Stoics in Roman society tolerated slavery, they were not fully virtuous. ${ }^{4}$ Lisa Tessman goes a step further, contending that because the majority of societies perpetuate systems of oppression, most people are not virtuous:

2 For work in linguistics on the distinction between the two types of adjectives, see Kennedy, "Vagueness and Grammar"; Kennedy and McNally, "Scale Structure and the Semantic Typology of Gradable Predicates"; and Rusiecki, On Adjectives and Comparisons in English.

3 Notable exceptions within the philosophy literature include Unger, Ignorance, and the recent discussion of aesthetic adjectives in Liao and Meskin, "Aesthetic Adjectives"; Liao, McNally, and Meskin, "Aesthetic Adjectives Lack Uniform Behavior"; Phelan, "Gradability and Multidimensionality in Aesthetic Adjectives"; and Stojanovic, "An Empirical Approach to Aesthetic Adjectives."

4 Annas, Intelligent Virtue, 63-64. 
Given the pervasive injustice of oppression, the high level of participation in maintaining structures of oppression, and the difficulty of unlearning traits associated with domination even for those who become critical, I see unjust and other vicious people as fairly ordinary. ${ }^{5}$

Tessman thinks that Annas's hunch is correct-people who fall short in some way are the typical case. The person who accepts the unjust inequalities at play in their society harbors some vice, an issue faced by the Roman Stoics as well as citizens of contemporary societies, and unless they actively resist such evils they compromise their own characters. Thus, it was just as Diogenes thought—virtuous persons are exceedingly rare.

Like with Diogenes's stance, the charge against Annas's and Tessman's accounts of virtue is that they are too demanding. Even though we live in a society that condones certain oppressive social arrangements, we surely know numerous virtuous people who share our cultural heritage. Annas expresses such a concern about her own account, worrying that the picture she has put forward is too far out of reach:

On this account, does virtue not turn out to be too ideal? While we have seen that thinking in terms of virtue can lead people to act virtuously in ways that go beyond their society and the ways of thinking they have grown up in, it might seem that even this will not render them fully virtuous. For they might be like the Roman Stoics, stuck with a society in which acting effectively in a fully virtuous way was not feasible.... Is virtue then an ideal which we can never hope to attain because of the contingency of living in societies which are always in some respect unjust? ${ }^{6}$

Annas is concerned that taking Diogenes's critique seriously undermines the thought that anyone is virtuous. If a person's virtue can be compromised even by participating in an unjust society, then such a charge indicts most, if not all, of the supposedly virtuous people who have lived. This criticism then suggests that no one has been virtuous, with none reaching the ideal that virtue holds out for us to attain. ${ }^{7}$

5 Tessman, Burdened Virtues, 56.

6 Annas, Intelligent Virtue, 64.

7 By the demandingness objection, I will mean the thought that even a bit of vice is enough to make one vicious. Owen Flanagan argues that there is no such thing as perfectly fulfilling all the virtues because the virtues may come into conflict (Varieties of Moral Personality, 33). Even if this point is correct, my thesis applies not only to what is required to possess all the virtues, but a single virtue as well. For a response to Flanagan, see Swanton, "Virtue Ethics and the Problem of Demandingness." 
In response to this criticism, it is possible to lean on a threshold account of virtue. It could well be that whether or not a person is virtuous depends not just on their character but also on the situation in which they find themselves. It is thus possible for a Roman Stoic to be virtuous just so long as they are virtuous enough for their particular context. Christine Swanton provides just such an account, giving the following threshold analysis of virtue:

A virtue is a good quality of character, more specifically a disposition to respond to, or acknowledge, items within its field or fields in an excellent or good enough way. ${ }^{8}$

According to Swanton, whether or not the Athenian or the Roman Stoic is virtuous depends not on whether they are fully in accord with virtue, as Annas and Tessman argue, but whether they are doing well enough given their situation. Dan Russell follows suit, characterizing virtue as being virtuous enough:

It seems undeniable that being virtuous enough is a sufficient condition for being virtuous tout court — not perfectly virtuous or even virtuous without qualification, but nonetheless virtuous in a genuine, bona fide sense. ${ }^{9}$

Even if the ideal of virtue is unattainable, resting on a contextual account of virtue allows that persons might be virtuous despite the society in which they find themselves. All that is required is that they be virtuous enough for the context in which they find themselves, even if that culture is one that condones slavery or other oppressive social arrangements.

In the remainder of this paper, I will argue that contextual accounts of virtue cannot capture the behavior of all virtue-theoretic adjectives. A number of virtue terms are absolute gradable adjectives, and as such are not context sensitive. Instead, it is only true to call someone virtuous if they instantiate virtue to the maximal degree. This position also resolves a potential ambiguity in Annas's and

8 Swanton, Virtue Ethics, 19, emphasis added.

9 Russell, Practical Intelligence and the Virtues, 112. Even though Russell and Swanton both invoke a threshold view of virtue, only Swanton makes her view explicitly contextual: "The standards for virtue should reflect the fact that the world is marred by the difficulty of attaining (full) virtue, and the all too frequent occurrence of catastrophe, scarcity, evil, and conflict. The standards for meeting thresholds of virtue are thus plural, in the sense of contextual, and what is salient and important for behaviour to count as displaying virtue will vary" (Virtue Ethics, 3). While it is conceptually possible that a variety of gradable adjectives have a non-contextual threshold, this possibility is not currently a serious competitor in the linguistics literature. Because my goal is to bring work on the semantics of gradable adjectives to bear on virtue ethics, I thus only evaluate the possibility that virtue-theoretic adjectives are either relative or absolute. 
Tessman's positions. Annas frames her worry in terms of whether the Roman Stoics can be fully virtuous, while Tessman is concerned about whether ordinary citizens are virtuous at all. If we take virtue to be a threshold concept, then virtue can come apart from full virtue, making the worries of Annas and Tessman generate separate concerns. When we take virtue to be full virtue, however, then the criticisms of Annas and Tessman are one and the same. The Roman Stoics not only fall short of full virtue, but thereby fail to be virtuous full stop. ${ }^{10}$

\section{RELATIVE AND ABSOLUTE GRADABLE ADJECTIVES}

\subsection{Relative Gradable Adjectives}

Gradable adjectives come in two forms: relative gradable adjectives and absolute gradable adjectives. ${ }^{11}$ A relative gradable adjective (RGA), such as "long," "small," and "short," draws some of its semantic characteristics from the fact that it has an underlying degree scale. Objects are placed along the underlying scale, making use of comparatives true or false. ${ }^{12}$ For example, 1 is true just in case the rod has a greater degree of length than the stick:

1. The rod is longer than the stick.

The most distinctive characteristic of RGAs, however, is their use of a contextual commitment to any particular understanding of virtue, Aristotelian or otherwise, but it is possible that the results of this paper will bear on such proposals. Just as the view I will argue for undercuts satisficing accounts of the virtues, it may be that arguing that some virtue terms are AGAs has other theoretical implications as well. Thank you to an anonymous reviewer for encouraging me to specify how I understand the arguments of this paper to apply to more detailed accounts of the virtues.

11 Kennedy, "Vagueness and Grammar"; Kennedy and McNally, "Scale Structure and the Semantic Typology of Gradable Predicates"; Rotstein and Winter, "Total Adjectives vs. Partial Adjectives"; Rusiecki, On Adjectives and Comparisons in English; and Unger, Ignorance.

Though the scale approach of Cresswell ("The Semantics of Degree"), Heim ("Degree Operators and Scope"), Kennedy ("Vagueness and Grammar"), and von Stechow ("Comparing Semantic Theories of Comparison") has been the most influential, the primary competitor is a view on which the extension of a gradable adjective displays contextual shifts with the basis for comparatives being quantifications over possible precisifications of the adjective's extension, a view whose development runs through Fine, "Vagueness, Truth, and Logic"; Kamp, "Two Theories of Adjectives"; Klein, "A Semantics for Positive and Comparative Adjectives"; Larson, "Scope and Comparatives"; and Pinkal, Logic and Lexicon. The scale view holds a distinct advantage though in explaining the distinction between relative and absolute adjectives (Kennedy, "Vagueness and Grammar"). 
threshold. The ordering on the underlying scale is not all that goes into whether 2 is true:

2. The rod is long.

Whether 2 is true or not requires not only an ordering on the underlying scale but also a threshold. If the rod's length is clearly greater than the threshold, then 2 is true, and if the degree of its length is clearly lower, then 2 is false. ${ }^{13}$ This threshold is also contextually determined. For example, the length of hair that an infant must possess in order to have long hair is less than the length of hair that an adult must have in order to be truthfully described as having long hair. The truth of 2 , then, requires not only an underlying scale but also a contextually adjustable threshold.

Since RGAs have a context-sensitive threshold, it is possible to use this threshold to distinguish between two objects that differ on the underlying scale. ${ }^{14}$ As specified before, the degree to which the object possesses the property must "stand out" relative to the threshold. ${ }^{15}$ Assuming that this condition is satisfied, in a selection task with two pieces of metal pipe, 3 is felicitous when one pipe is clearly longer than the other even if the pieces are not particularly long:

3. Point to the long one.

Statement 3 is a felicitous request due to the contextually variable threshold on the underlying scale. This threshold, however, is not endlessly accommodat-

13 For more on determining the truth conditions of relative gradable adjectives, see Rotstein and Winter, "Total Adjectives vs. Partial Adjectives"; Kennedy, "Vagueness and Grammar" and "Vagueness and Comparison"; and Kennedy and McNally, "Scale Structure and the Semantic Typology of Gradable Predicates." The core idea is that, in order to accommodate cases of vagueness, the objects that fall within the extension of an RGA must "stand out" relative to the contextual threshold, a view that has a lengthy history. See Barker, "The Dynamics of Vagueness"; Bartsch and Vennemann, "The Grammar of Relative Adjectives and Comparison"; Bierwisch, "The Semantics of Gradation"; Cresswell, "The Semantics of Degree”; Fine, "Vagueness, Truth, and Logic"; Kamp, "Two Theories of Adjectives"; Klein, "A Semantics for Positive and Comparative Adjectives"; Lewis, "General Semantics"; Ludlow, "Implicit Comparison Classes"; Pinkal, Logic and Lexicon; Sapir, "Grading"; von Stechow, "Comparing Semantic Theories of Comparison"; and Wheeler, "Attributives and Their Modifiers."

14 See Kennedy, "Vagueness and Grammar"; Kyburg and Morreau, "Fitting Words"; Sedivy et al., "Achieving Incremental Semantic Interpretation through Contextual Representations"; Syrett et al., "Shifting Standards"; and Syrett, Kennedy, and Lidz, "Meaning and Context in Children's Understanding of Gradable Adjectives."

15 See Rotstein and Winter, "Total Adjectives vs. Partial Adjectives"; Kennedy, "Vagueness and Grammar" and "Vagueness and Comparison"; and Kennedy and McNally, "Scale Structure and the Semantic Typology of Gradable Predicates." 
ing - at the extreme parts of the scale, 3 is not always felicitous. Consider, for example, two roads, one that is seven thousand miles long and the other that is eight thousand miles long. The infelicity of 3 in such a case demonstrates that the contextual threshold at issue with RGAs does not have an unbounded ability to distinguish between objects that differ on the underlying scale.

Another feature of RGAs is that they always give rise to Sorites paradoxes. With "long," the paradox gets going with 4 :

4. For whatever length an object is, one centimeter of length does not change whether it is long or not.

The trouble of course is created by the fact that 4 seems true. This can be explained by the fact that RGAs cannot be used to pick out a maximally specific point on the underlying scale. As previously noted, an object falls with the extension of an RGA like "long" if it possesses a degree of height that is clearly greater than the relevant threshold, a description meant to accommodate for borderline cases. Even though there are roads that are obviously long and others that are not, for some it is unclear whether they should be classified as long or short. This vagueness makes it such that 4 is intuitively correct, leading to the Sorites. ${ }^{16}$

\subsection{Total and Partial Absolute Gradable Adjectives}

Just like RGAs, absolute gradable adjectives, words that include "closed," "healthy," "pure," and "straight," can be used comparatively. Based on their position on the degree scale, objects can be compared and contrasted, with a use of 5 being true so long as the road is closer to 180 degrees than the river:

5. The road is straighter than the river.

As with RGAs, however, the underlying scale is not the only thing that accounts for the truth of the unmarked form in 6:

6. The road is straight.

Just like with RGAs, 6 is true only if the road is straight to a particular degree. In contrast to RGAs, however, this degree does not change according to context. Even when one stick is clearly straighter than another stick, if they are both somewhat bent, 7 is infelicitous:

7. \#Point to the straight one.

16 For evaluations of what types of semantic accounts of gradable adjectives can diagnose the existence of borderline cases and the Sorites paradox, see Graff Fara, "Shifting Sands"; Kennedy, "Vagueness and Grammar"; Pinkal, Logic and Lexicon; and Rusiecki, On Adjectives and Comparisons in English. 
Unlike an RGA, then, an absolute gradable adjective (AGA) does not have a threshold that is contextually accommodating. ${ }^{17}$

It might seem that the difficulty with 7 is the same problem that we encountered with the two very long roads. Why not say that there are parts of the degree scale that both unmarked RGAs and AGAS are incapable of distinguishing between? The difference between the two is that, whereas the infelicity of 7 occurs in the middle of the underlying scale, the trouble with 3 happens at the extremes of the scale. The sticks are both slightly bent, whereas the roads are thousands of miles long. If we change the situation though, using the AGA at the extreme end of the scale, the situation shifts. In this case, the AGA will be able to distinguish between the two objects. If we have a perfectly straight stick and one that is slightly bent, then 7 is felicitous. Instead of getting the result that the problem with the long roads and 3 and the two bent sticks with 7 is the same issue, these difficulties actually reinforce the contrast between AGAS and RGAS. AGAS pass the "point to" test at the extreme ends of their scales but not in the middle, while RGAs pass the test in the middle of their scales but not at their extremes.

Further distinguishing AGAs from RGAs is that they do not always create Sorites paradoxes. Their lack of contextual threshold allows them to pick out a maximally specific point, making Sorites-driving principles intuitively unappealing. If a stick is bent just one degree, then 8 does not have the same pull as 4 :

8. For however bent a stick is, one degree of bend does not change whether it is straight or not.

For a stick that is one degree from being straight, 8 is false-straightening the stick by one degree does make the stick straight. This is due to the clear boundary between being straight and not being straight. There is not a similar boundary, however, with "long," making the Sorites-paradoxical result inevitable for it and other RGAs. ${ }^{18}$

Just as gradable adjectives can be differentiated into relative and absolute, it is possible to distinguish absolute gradable adjectives as total and partial. Total AGAS are distinguished by picking out an end point on the underlying scale. A

17 See Aparicio, Miang, and Kennedy, "Processing Gradable Adjectives in Context"; Kennedy, "Vagueness and Grammar"; Kyburg and Morreau, "Fitting Words"; Qing and Franke, "Gradable Adjectives, Vagueness, and Optimal Language Use"; Sedivy et al., "Achieving Incremental Semantic Interpretation through Contextual Representations"; Syrett et al., "Shifting Standards"; and Syrett, Kennedy, and Lidz, "Meaning and Context in Children's Understanding of Gradable Adjectives."

18 Burnett ("A Delineation Solution to the Puzzles of Absolute Adjectives"), Kennedy ("Vagueness and Grammar"), and Pinkal (Logic and Lexicon), all point out cases in which absolute gradable adjectives avoid the Sorites. 
straight line is not bent to any degree and a closed door is not at all open. Partial AGAs, on the other hand, are used truthfully when an object deviates from the end of the scale. One degree off from straightness counts as bent, just as a door being ever so slightly ajar makes it open. ${ }^{19}$ As with the two examples currently in focus - straight/bent and closed/open_-AGAs often come in total/partial pairs. This corresponds to whenever AGAs are contradictories, as "bent" is synonymous with "not straight" and "open" with "not closed." How to distinguish between total and partial AGAs? A common test for whether a gradable adjective has a top-closed scale is whether the modifier "completely" can be used to pick out a maximal element. ${ }^{20}$ Such constructions are thus felicitous for total AGAs:

9. The door is completely closed.

10. The stick is completely straight.

11. The gold is completely pure.

RGAs, however, do not accept similar attempts at modification:

12. The road is completely long.

Partial AGAs sometimes do accept the modifier "completely," but not because they have top-closed scales. One instance in which this occurs is when "completely" functions as synonymous with "very," as in 13:

13. The stick is completely bent.

The use of "completely" in 13 can be seen to be synonymous with "very" using an entailment test. When "completely" is synonymous with "very," it is possible that something can possess the partial AGA to an even greater degree, while when "completely" is used to pick out the maximum degree on a scale with a total AGA, this is not possible. ${ }^{21}$ Suppose that a mechanic is comparing two exhaust pipes, both so bent that they are no longer roadworthy. In such a case, 14 is felicitous:

19 For more on the distinction between total and partial absolute adjectives, see Burnett, "A Delineation Solution to the Puzzles of Absolute Adjectives"; Cruse, Lexical Semantics; Kamp and Rossdeutscher, "DRs-Construction and Lexically Driven Inferences”; Kennedy, "Vagueness and Grammar"; Rotstein and Winter, "Total Adjectives vs. Partial Adjectives"; and Yoon, "Total and Partial Predicates and the Weak and Strong Interpretations."

20 See Burnett, "A Delineation Solution to the Puzzles of Absolute Adjectives"; Cruse, Lexical Semantics; Kennedy, "Vagueness and Grammar"; Kennedy and McNally, "Scale Structure and the Semantic Typology of Gradable Predicates”; and Rotstein and Winter, “Total Adjectives vs. Partial Adjectives."

21 See Kennedy and McNally, "Scale Structure and the Semantic Typology of Gradable Predi- 
14. This pipe is completely bent, but that other exhaust pipe is bent even further.

It is not felicitous, however, to say 15:

15. \#That pipe is completely straight, but it could still be straightened just a bit more.

A useful diagnostic for testing for the presence of a closed scale is modifying a gradable adjective with "completely." The test is not foolproof-we have seen that in some cases "completely" permits of non-maximal interpretations-but if an adjective has a maximum on its underlying scale, then it should accept modification by "completely."

\section{VAGUENESS AND IMPRECISION}

Even though total AGAs function without a contextually accommodating threshold and pick out the endpoint on the underlying scale, contexts can be created in which approximate uses of total AGAs are acceptable. When the purpose of drawing a straight line is to illustrate a rough line graph, then a line that is off by a few degrees can be called straight. Likewise, there are situations in which it is acceptable to call a door closed even if it has not completely slammed shut. In these types of situations, total AGAs can generate a Sorites, for it is difficult to say whether one more degree of bend will make the line less than straight, or whether being an inch more open will change the status of the door from closed to open.

The fact that uses of total AGAs can create issues with the Sorites raises some difficult questions. On what grounds can we say that the contextual variation at issue with total AGAs is not, like that of RGAs, that of a contextual threshold? Does the fact that AGAs permit some variety of context shifting enough to undermine the thought that they are distinct from RGAs? As we have seen, AGAs display a distinct profile when it comes to the "point to" test, so we have good grounds for saying that they function differently from RGAs. Using this as our starting point, it can also be argued that the best way to characterize the contextual variation permitted by AGAS is, unlike RGAs, that of imprecision. ${ }^{22}$ With

cates," 354 .

22 For work on imprecision as it relates to absolute gradable adjectives, see Pinkal, Logic and Lexicon; and Kennedy, "Vagueness and Grammar." For more on imprecision more generally, see Krifka, "Be Brief and Vague!" and "Approximate Interpretations of Number Words"; Lakoff, "Hedges"; Sadock, "Truth and Approximations"; and Sauerland and Stateva, "Scalar vs. Epistemic Vagueness" and "Two Types of Vagueness." 
imprecise terms, a particular point plays a privileged role in its meaning. Consider, for instance, saying that a rod is ten inches long. The exact length of ten inches plays a critical role in the meaning of "ten inches" even though there are situations in which it is acceptable to use this locution imprecisely. If a stick is nine inches long, no one will raise much of a fuss if it is described as being ten inches, but this does not tell against the fact that the precise length of ten inches is central to its meaning. With total AGAs, we can think of the endpoint of the scale as taking on the role of being exactly ten inches long. Even though there are cases in which it can be acceptable to use "ten inches" and "straight" imprecisely, this does not undermine the thought that an exact point captures the meaning of the terms. Thus, the contextual variability permitted by AGAs is not due to a contextual threshold, differentiating AGAs from RGAs.

Further corroborating the thought that AGAS differ from RGAs in allowing imprecise use, AGAS allow what is known as natural precisification. Vague terms can only be made more precise by stipulation, whereas imprecise terms can be precisified simply by particular uses in natural-language contexts. If a construction worker provides a plank that is eleven inches long, the contractor can reject the board saying:

16. The length of the board needs to be ten inches, but this one is only nine inches so it will not do.

With a use of 16, the foreman eliminates imprecise uses of "ten inches" from consideration. Such precisification cannot occur with RGAs. Suppose, for example, that the foreman wants a long steel girder, over one hundred feet, to serve as one of the supports of a skyscraper. He cannot precisify the meaning of "long" to that of a precise value with a use of 17 :

17. I need a long girder, but this one is only ninety feet so it will not do.

Even though the foreman needs a steel girder that is over one hundred feet long, he cannot communicate this by precisifying the meaning of "long" using 17 like the contractor can precisify the meaning of "ten inches" with 16 . Instances of imprecision can be revealed, then, by the possibility of natural precisification.

What about total AGAs? Do they permit natural precisification? Consider: a satellite needs a perfectly straight antenna in order to make proper readings. If an antenna is slightly curved, an engineer can reject it with 18 :

18. The antenna needs to be straight, but this one is slightly curved so it will not do.

Statement 18 can be used to disallow any imprecise applications of "straight." 
"Straight" is far from the only total AGA that allows natural precisification. If a parent wants to prevent intruders from entering their home during the night, they can chastise their children with 19 even if the door was just barely cracked open:

19. We are trying to make sure that no one comes in while we are sleeping, so next time the door needs to be closed.

The use of "closed" in 19 will not allow any imprecision-only being completely closed will be acceptable with this precisified meaning of "closed." Thus, it appears that total AGAS do accept natural precisification, confirming that they can be used imprecisely.

Our discussion thus far has revealed some important features of acceptable imprecision. Imprecision is permitted whenever it does not interfere with the practical purposes at hand. Sometimes a board that is approximately ten inches is all that is needed, and in such cases, imprecise uses of "ten inches" will be acceptable. Likewise, rough lines and slightly open doors can sometimes do the job, and it is in these situations that imprecise uses of "straight" and "closed" are permissible. This realization, that the practical circumstances regulate acceptable imprecise attributions, can also be used to respond to critics. Assaf Toledo and Galit Sassoon criticize the orthodox view of AGAs, arguing that the account does not stand up to natural-language data. ${ }^{23}$ In particular, they present the following, supposedly problematic, examples:

20. This kitchen knife is clean.

21. This surgical instrument is clean.

22. This child's shirt is dirty.

23. This tuxedo is dirty.

If total AGAs are used to picked out the maximal element on the underlying scale, then why are uses of 20 and 22 acceptable in cases of cleanliness and dirtiness that are less stringent than is required for uses of 21 and 23 ? According to Toledo and Sassoon, such cases show that the interpretation of AGAs depends on more than just an end point in a scale. They claim that other features come into play as well, like the object type to which the total AGA is being applied, undermining the standard account of the semantics of AGAs.

An obvious rejoinder to Toledo and Sassoon is to take what we have articulated about permissible imprecision and apply it to 20-23. Imprecision is al- 
lowed whenever the purposes at hand can be satisfied, and in the case of kitchen knives and surgical instruments, it is worth noting that they are typically used with quite distinct purposes in mind. Surgical instruments must be cleaned of all microscopic bacteria, whereas kitchen utensils only need to be cleansed to be rid of food scraps that are visible to the naked eye. Thus, the standards for an attribution of 21 are much more stringent than a use of 20, explaining how they can come apart appealing only to the mechanisms of imprecision. Similarly, tuxedos are worn in circumstances where being spotlessly clean is the norm, so acceptable uses of 23 require less dirt than those of 22 . For this reason, the objections of Toledo and Sassoon can be accommodated by the previous discussion of allowable imprecision. Imprecise use is countenanced whenever it does not interfere with the purposes at hand, predicting that acceptable uses of 20 and 22 will come apart from acceptable applications of 21 and 23.

\section{VIRTUE TERMS AS ABSOLUTE GRADABLE ADJECTIVES}

\subsection{The Virtue-Theoretic AGAS}

All virtue-related adjectives are obviously gradable, as they can be used both with degree modifiers and comparatively:

24. Susan is more virtuous/honest/just than Mark.

25. Susan is very virtuous/honest/just, the most virtuous/honest/just person I know.

The gradability of virtue terms, however, is not what is at issue between the contextual threshold view and the absolute account. What matters is the behavior of the unmarked form of virtue-theoretic adjectives, the sorts of tests that distinguish between RGAS and AGAS.

Before getting into these tests, it is important to note a couple of characteristics of virtue terms. To begin with, a number of object types accept modification by virtue-related adjectives. Since our focus is on virtue ethics, the examples I consider will employ actions and persons, the object types relevant to virtue ethics. Another difficulty to flag is that being honest or just, or being virtuous more generally, is not simply a product of concrete actions. Virtues are dispositional, and as such are vulnerable to masking and otherwise failing to manifest. A dishonest person can have told no lies, even though they are so predisposed, simply by having no opportunities to lie. Thus, we will not only look at examples of occurrent actions, but merely possible actions as well. On then to the tests.

At both the middle and the extremes of their scales, a number of virtue-the- 
oretic adjectives, including "honest," "just," and "virtuous," function like AGAs. Let us start with honest. Suppose that Susan and Mark are both relatively middling when it comes to honesty — not perfectly honest, but also not egregious liars: Mark has told four white lies this week and Susan only two. Even though 24 is true, the request in 26 is infelicitous:

26. \#Point to the honest/virtuous person.

It thus appears that "honest" is an AGA, a thought confirmed by the fact that if Susan has told no lies and Mark has told two then 26 is acceptable. When we have someone who is perfectly honest, we have arrived at the end of the scale, and it is here that the "point to" test is felicitous for AGAs.

Because the scale of honesty has an end point, there are also cases in which it does not permit the Sorites. For example, 27 is clearly false when considering the difference between telling one lie or none at all:

27. For however dishonest a person is, telling one less lie will not make them honest.

Of course, we noted earlier that it is not merely the telling of lies that makes one dishonest, but also the disposition to tell lies. To account for this, we can alter 27 as follows:

28. For however dishonest a person is, the disposition to tell one less lie will not make them honest.

With 28 , we are not simply altering the manifestations of the person's dispositions, but whether they have the disposition altogether. Changing a person from being disposed to tell a lie in a particular scenario to no longer being so disposed does in fact change whether or not they are honest, preventing the Sorites from getting started.

Both of these results also obtain with the virtue of justice. Consider: Susan and Mark are both business owners. For the same task, Susan pays one of her workers twenty dollars and another fifteen dollars. Mark, though, is even worse. He pays one employee twenty dollars and the other five dollars even though they perform the same amount of labor. Statement 24 is applicable in this case, as Susan is more just than Mark, but nevertheless, both the commands in 29 and 30 are unacceptable:

29. \#Point to the just/virtuous person.

30. \#Point to the owner who justly paid their employees. 
Just as the "point to" test fails in the middle of the scale, though, it succeeds at the end of the scale. If Susan pays both of her staff members twenty dollars while Mark pays one twenty dollars and the other nineteen, we can differentiate between them with the unmarked form of just in 29 and 30 . This result holds up in relation to the Sorites as well. At the end of the scale, 31 is false, depriving the paradox of its crucial premise:

31. For however unjust a person is, paying their employees a dollar more will not make them just.

The case is very clear. Both "honest" and "just" behave as AGAs with the Sorites as well as the "point to" test.

Interestingly enough, the arguments for the absolute accounts of honesty and justice are also arguments that being virtuous requires being perfectly virtuous. When 24 is infelicitous for "honest," it is also infelicitous for "virtuous," and likewise, whenever 29 is unacceptable for "just," it is unacceptable for "virtuous." The same is true of natural precisification. Virtue terms are sometimes used to rule out those that are quite vicious. If a job candidate lies several times on an application, a manager could refuse to consider them with a use of 32 :

32. We need someone who is honest/virtuous.

On other occasions though, virtue language can be used to rule out those who are vicious even to a small degree. Suppose that an intelligence agency is hiring a spy and, in the course of their interview, even though they do not lie, they nevertheless fail to divulge one of their previous marriages. Intelligence staff may move on from the candidate with a use of 32 even though the candidate is very honest, a much stronger standard than someone who outright lies on their application. Likewise, suppose that a police officer is being considered for a junior-level promotion, but it is found that he arrested someone purely on the basis of their race. The committee should dismiss them with a use of 33:

33. We need someone who is just/virtuous.

The same locution can be used, however, for even a minute breech of justice. If it comes to light that the would-be sheriff passed over one of his friends for their routine traffic violation, 33 can be given as a justification for preventing him from assuming his new post. Terms for the individual virtues, as well as the more general "virtuous," are thus subject to natural-language precisification depending on the practical task at hand, providing compelling evidence that they are all AGAS. 


\subsection{Are All Virtue-Related Adjectives AgAs?}

It is clear that a number of virtue terms are AGAs. As we have seen, "virtuous," "honest," and "just," all pass the "point to" and precisification tests for AGAs, making it clear that they are distinct from RGAs. A further question, however, is whether all virtue-theoretic adjectives are AGAs. Take, for example, another test we considered in section 2, modification by "completely." All of the three virtue terms discussed thus far pass the "completely" test:

34. Susan is completely virtuous/honest/just.

Each of "virtuous," "honest," and "just" has no issue being modified by "completely," exactly what we should expect from AGAs. There are other virtue terms, however, that present difficulties. Consider, for example, "courageous" and "generous":

35. \#Susan is completely generous/courageous.

Statement 35 is not as obviously felicitous as are all the variations of 34 , calling into question both whether all of the virtues have maximal-degree interpretations as well as whether all virtue-related adjectives are AGAs.

How should we make sense of the infelicity of 35 ? One possibility is that the "completely" test does not totally bifurcate RGAs from AGAs. "Courageous," for example, functions in the "point to" test as an AGA in the middle of its scale. If Mark hides in his foxhole while Susan wills herself out of the trench but then is overcome with cowardice at the gates of the enemy's fortress, 36 is infelicitous:

36. \#Point to the person whose war effort was courageous.

Had Susan continued to infiltrate the enemy stronghold, 36 would have been an acceptable request, and so there is at least one data point that supports an AGA interpretation of "courageous." It also makes sense to think of courage as the absence of any cowardice, making "courageous" and "cowardly" a total/partial pair. One verdict to draw in this case then is that modification by "completely" is not an infallible test for diagnosing AGAs.

Another way to interpret the infelicity of 35 is to say that some virtue terms, like "generous" and "courageous," are not AGAs like the other virtue-theoretic adjectives we have surveyed. The difficulty with going this route is that it makes it challenging to understand what maximal virtue would be like. "Virtuous" is a multidimensional adjective in that there are multiple factors that determine whether it applies. One way of understanding perfect virtue, then, is to understand it as perfection in all of its underlying dimensions, a conjunctive, multidi- 
mensional adjective that only applies when all of its more basic elements apply. "Vicious," then, is a disjunctive multidimensional adjective in that any element of vice is enough to make one vicious. ${ }^{24}$ If generosity and courage, however, do not have maxima, how should we understand "virtuous"? It could be that, of virtue's underlying dimensions, some require perfection while others only call for jumping over a contextual threshold.

Such a picture necessarily complicates the picture of what complete virtue is like, raising the question of why open-ended underlying virtues fail to also make "virtuous" an RGA. Suppose, for example, that "generous" is an RGA and generosity has an open scale. If two people are both above the threshold for "generous" on the underlying scale, then even if one is more generous than the other, this may not make one more virtuous than the other. If they are both completely virtuous, that is, if all the virtue terms truly apply to them, then the fact that "virtuous" is an AGA predicts that it will be false to say that one person is more virtuous than the other. This would be a surprising result, that the RGA nature of some of the underlying virtues does not "bubble up" to make "virtuous" itself an RGA. Thus, taking virtue terms to be a mixed bag of RGAS and AGAS also creates difficulties.

\subsection{Virtue and Context}

Despite the issues raised by 35 , the argument of this paper is that a number of the virtues require perfection, and this only necessitates that some of the virtues be AGAs. As we have seen, this is true of "honest," "just," and perhaps "virtuous," a point that is significant even if it does not generalize to all virtue-related adjectives. Whether or not all virtue-theoretic adjectives are in fact AGAs is beyond the scope of this paper, so at this juncture I would like to turn to the lessons that can be learned from the virtue terms that are AGAs.

Because some virtue terms are AGAs, their meanings are fixed on their maximal degrees. In order for it to be true that an Athenian is honest, they must be completely honest, and for it to be true that a Roman Stoic is just, they must be completely just. It is possible to speak, as we often do, of honest parents, honest teachers, and honest friends, but all of these attributions are instances of imprecision and ultimately false. This is not to say that imprecise uses of virtue-theoretic adjectives do not have their place; such uses can have practical value. A theory of virtue, though, does not have to answer to imprecise applications of the concept. The fact that many virtue terms are AGAs also means that Swanton's and

24 For more on the typology of multidimensional adjectives, see Sassoon, "A Typology of Multidimensional Adjectives." Thank you to an anonymous reviewer for suggesting that I note the multidimensional nature of "virtuous." 
Russell's threshold views cannot account for all of the behavior of virtue terms. For some virtues, it is not enough to be virtuous to simply be good enough for one's circumstances. Strictly speaking, it is true that a person is honest, just, or virtuous only if they are perfectly honest, just, or virtuous.

Diogenes was right to think that there were very few, if any, virtuous Athenians. Given that they lived in a corrupting society, it was very difficult, if not impossible, to be completely virtuous. Similarly, Annas and Tessman do not need to worry that their accounts seem particularly demanding. ${ }^{25}$ It turns out that the nature of virtue is demanding - it is only true to say that someone is virtuous if they are perfectly virtuous - and so it is no surprise that participating in a society of systematic oppression compromises the virtue of its citizens. ${ }^{26}$

The arguments of this paper may have wider application. Just as they have shown that it is almost impossible to be virtuous in an unjust society, they could also be used to show that it is very challenging to be virtuous under a just political order. The problem of unjust societies, however, is a particularly poignant case, one that calls to mind quite readily the possibility that virtue terms are context sensitive. The rejection of such an account in favor of the view that a number of virtue-theoretic adjectives are absolute has far-reaching implications for theorizing about virtue, implications that may indeed reach far beyond the problem of unjust societies. ${ }^{27}$

\author{
University of Arizona \\ rwsiscoe@email.arizona.edu
}

25 Even though the current account vindicates Annas's view on virtue in unjust societies, it does not support her understanding of virtue in all cases. Annas, for instance, says "Being truly (or perfectly) virtuous is indeed an ideal which none of us can exemplify. But it does not follow that none of us are brave, loyal, or generous" (Intelligent Virtue, 65). On the present view, if any of "brave," "loyal," or "generous" are AGAs, then any cases in which it is acceptable to say that we are brave, loyal, or generous when we are not completely so are strictly speaking false virtue attributions.

The view that some virtues are AGAs is compatible with either view in the debate over whether external goods are merely instrumental to virtue or partially constitutive of virtue. The view that one takes on the external goods question may well have consequences for what full virtue requires, but the absolute view can be made consistent with either view on the role of external goods in becoming virtuous.

27 For helpful discussion and input on this project, I am indebted to Maria Altepeter, Julia Annas, Stew Cohen, Juan Comesana, Christopher Kennedy, Daniel Nolan, Nathan Oakes, Jeremy Reid, Tristan Rogers, Jackie Sideris, Joshua Stuchlik, Bjorn Wastvedt, Jonathan Weinberg, Sean Whitton, and two anonymous reviewers from this journal. 


\section{REFERENCES}

Annas, Julia. Intelligent Virtue. Oxford: Oxford University Press, 2011.

Aparicio, Helena, Ming Xiang, and Christopher Kennedy. "Processing Gradable Adjectives in Context: A Visual World Study." Proceedings of SALT 25 (2015): 413-32.

Barker, Chris. “The Dynamics of Vagueness." Linguistics and Philosophy 25, no. 1 (February 2002): 1-36.

Bartsch, Renate, and Theo Venneman. "The Grammar of Relative Adjectives and Comparison." Linguistische Berichte 21 (1972): 19-32.

Bierwisch, Manfred. "The Semantics of Gradation." In Dimensional Adjectives, edited by Manfred Bierwisch and Ewald Lang, 71-261. Berlin: Springer-Verlag, 1989.

Burnett, Heather. "A Delineation Solution to the Puzzles of Absolute Adjectives." Linguistics and Philosophy 37, no. 1 (February 2014): 1-39.

Cresswell, Max. "The Semantics of Degree." In Montague Grammar, edited by Barbara Partee, 261-92. New York: Academic Press, 1977.

Cruse, D. A. Lexical Semantics. Cambridge: Cambridge University Press, 1986.

Fine, Kit. "Vagueness, Truth, and Logic." Synthese 30, no. 3/4 (April-May 1975): 265-300.

Flanagan, Owen. Varieties of Moral Personality: Ethics and Psychological Realism. Cambridge, MA: Harvard University Press, 1991.

Fox, Sue. Etiquette for Dummies. Hoboken, NJ: John Wiley and Sons, 2011.

Graff Fara, Delia. "Shifting Sands: An Interest-Relative Theory of Vagueness." Philosophical Topics 28, no. 1 (Spring 2000): 45-81.

Heim, Irene. "Degree Operators and Scope." Proceedings of SALT 10 (2000): 4064 .

Kamp, Hans. "Two Theories of Adjectives." In Formal Semantics of Natural Language, edited by Edward Keenan, 123-55. Cambridge: Cambridge University Press, 1975.

Kamp, Hans, and Antje Rossdeutscher. "DRs-Construction and Lexically Driven Inferences." Theoretical Linguistics 20, no. 2-3 (January 1994): 165-235.

Kennedy Christopher. "Vagueness and Comparison." In Vagueness and Language Use, edited by Paul Égré and Nathan Klinedinst, 73-97. London: Palgrave Macmillan, 2011.

- "Vagueness and Grammar: The Semantics of Relative and Absolute Gradable Adjectives." Linguistics and Philosophy 30, no. 1 (February 2007): $1-45$. 
Kennedy, Christopher, and Louise McNally. "Scale Structure and the Semantic Typology of Gradable Predicates." Language 81, no. 2 (2005): 345-81.

Klein, Ewan. "A Semantics for Positive and Comparative Adjectives." Linguistics and Philosophy 4, no. 1 (March 1980): 1-45.

Krifka, Manfred. "Approximate Interpretations of Number Words: A Case of Strategic Communication." In Cognitive Foundations of Interpretation, edited by Gerlof Bouma, Irene Krämer, and Joost Zwarts, 111-26. Amsterdam: Koninklijke Nederlandse Akademie van Wetenschapen, 2007.

. "Be Brief and Vague! And How Bidirectional Optimality Theory Allows for Verbosity and Precision." In Sounds and Systems, Studies in Structure and Change: A Festschrift for Theo Vennemann, edited by David Restle and Dietmar Zaefferer, 429-48. Berlin: Mouton de Gruyter, 2002.

Kyburg, Alice, and Michael Morreau. "Fitting Words: Vague Language in Context." Linguistics and Philosophy 23, no. 6 (December 2000): 577-97.

Lakoff, George. "Hedges: A Study in Meaning Criteria and the Logic of Fuzzy Concepts." Journal of Philosophical Logic 2, no. 4 (October 1973): 458-508.

Larson, Richard. "Scope and Comparatives." Linguistics and Philosophy 11, no. 1 (February 1988): 1-26.

Lewis, David. "General Semantics." Synthese 22, no. 1-2 (December 1970): 18-67. Liao, Shen-yi, Louise McNally, and Aaron Meskin. "Aesthetic Adjectives Lack Uniform Behavior." Inquiry 59, no. 6 (2016): 618-31.

Liao, Shen-yi, and Aaron Meskin. "Aesthetic Adjectives: Experimental Semantics and Context-Sensitivity." Philosophy and Phenomenological Research 94, no. 2 (March 2017): 371-98.

Ludlow, Peter. "Implicit Comparison Classes." Linguistics and Philosophy 12, no. 4 (August 1989): 519-33.

McCarthy, Ed, and Mary Ewing-Mulligan. Wine for Dummies. Hoboken, NJ: John Wiley and Sons, 2015.

McNally, Louise. "The Relative Role of Property Type and Scale Structure in Explaining the Behavior of Gradable Adjectives." In Vagueness in Communication, edited by Rick Nouwen, Robert van Rooij, Uli Sauerland, and Hans-Christian Schmitz, 151-68. Berlin: Springer, 2011.

Phelan, Mark. "Gradability and Multidimensionality in Aesthetic Adjectives." Unpublished manuscript.

Pinkal, Manfred. Logic and Lexicon. Dordrecht: Kluwer, 1995.

Qing, Ciyang, and Michael Franke. "Gradable Adjectives, Vagueness, and Optimal Language Use: A Speaker-Oriented Model.” Proceedings of SALT 24 (2014): 23-41.

Rotstein, Carmen, and Yoad Winter. “Total Adjectives vs. Partial Adjectives: 
Scale Structure and Higher-Order Modifiers." Natural Language Semantics 12, no. 3 (September 2004): 259-88.

Rusiecki, Jan. On Adjectives and Comparisons in English. New York: Longman Linguistics Library, 1985.

Russell, Daniel. Practical Intelligence and the Virtues. Oxford: Oxford University Press, 2009.

Sadock, Jerrold. "Truth and Approximations." In Proceedings of the Third Annual Meeting of the Berkeley Linguistics Society, edited by Kenneth Whistler Jr., Robert D. Van Valin Jr., Chris Chiarello, et al., 430-39. Berkeley: Berkeley Linguistics Society, 1977.

Sapir, Edward. "Grading: A Study in Semantics." Philosophy of Science 11, no. 2 (April 1944): 93-116.

Sassoon, Galit. "A Typology of Multidimensional Adjectives." Journal of Semantics 30, no. 3 (August 2013): 335-80.

Sauerland, Uli, and Penka Stateva. "Scalar vs. Epistemic Vagueness: Evidence from Approximators." Proceedings of SALT 17 (2007): 228-45.

_- "Two Types of Vagueness." In Vagueness and Language Use, edited by Paul Égré and Nathan Klinedinst, 121-45. London: Palgrave Macmillan, 2011. Sedivy, Julie C., Michael K. Tanenhaus, Craig G. Chambers, and Gregory N. Carlson. "Achieving Incremental Semantic Interpretation through Contextual Representations." Cognition 71, no. 2 (June 1999): 109-47.

Stojanovic, Isidora. "An Empirical Approach to Aesthetic Adjectives." In Advances in Experimental Philosophy of Aesthetics, edited by Florian Cova and Sébastien Réhault, 221-40. London: Bloomsbury Academic, 2018.

Swanton, Christine. Virtue Ethics: A Pluralistic View. Oxford: Oxford University Press, 2003.

- "Virtue Ethics and the Problem of Demandingness." In The Problem of Moral Demandingness: New Philosophical Essays, edited by Timothy Chappel, 104-22. New York: Palgrave Macmillan, 2009.

Syrett, Kristen, Evan Bradley, Christopher Kennedy, and Jeffrey Lidz. "Shifting

Standards: Children's Understanding of Gradable Adjectives." Proceedings of the Inaugural Conference on Generative Approaches to Language Acquisition (2006): 353-64.

Syrett, Kristen, Christopher Kennedy, and Jeffrey Lidz. "Meaning and Context in Children's Understanding of Gradable Adjectives.” Journal of Semantics 27, no. 1 (February 2010): 1-35.

Tessman, Lisa. Burdened Virtues: Virtue Ethics for Liberatory Struggles. Oxford:

Oxford University Press, 2005.

Toledo, Assaf, and Galit Sassoon. "Absolute vs. Relative Gradable Adjectives: 
Variance Within vs. Between Individuals." Proceedings of SALT 21 (2011): 13554 .

Unger, Peter. Ignorance: A Case for Scepticism. Oxford: Clarendon Press, 1975.

Von Stechow, Arnim. "Comparing Semantic Theories of Comparison." Journal of Semantics 3, no. 1-2 (1984): 1-77.

Wheeler, Samuel. "Attributives and Their Modifiers." Noûs 6, no. 4 (November 1972): 310-34.

Yoon, Youngeun. "Total and Partial Predicates and the Weak and Strong Interpretations.” Natural Language Semantics 4, no. 3 (January 1996): 217-36. 